\title{
Physiotherapy and Rehabilitation in Congenital Facial Paralysis
}

\author{
ib Müberra TANRIVERDİ, id Büşra AKTAŞ, iD Arife Ceylan ÜSTÜN, iD Merve ÇAKIRCA, id Büşra YENER
}

Bezmialem Vakif University Faculty of Health Sciences, Department of Physical Therapy and Rehabilitation, İstanbul, Turkey

\begin{abstract}
Congenital facial paralysis (CFP) is a paralysis of facial nerve that occurs in birth or shortly after birth due to congenital or traumatic causes, has a prevalence of 1.2-2.4/1000. Our aim is to determine the effectiveness of physiotherapy and rehabilitation in CFP. We assessed a 9-year-old girl, who had no congenital injuries, with muscle test, House Brackmann Facial Grading Systems (HBFGS) and Sunnybrook Facial Grading Systems (SFGS). She got level 4 in HBFGS scale; and 20 points for resting symmetry, 72 points for voluntary movement symmetry and 4 points for synkinesis in SFGS scale. The patient received our treatment including face massage, electrotherapy, mimic muscle and functional exercises lasting one hour per session, 3 days a week for 24 weeks. Biopsychosocial positive feedback was obtained after the ongoing treatment program, although there were no numerical changes in assessment scales. Although reported cases in the literature are irreversible, studies on rehabilitation are needed.
\end{abstract}

Keywords: Congenital facial paralysis, physiotherapy, rehabilitation

\section{Introduction}

Facial paralysis is the paralysis of the VII. Cranial nerve (Nervus facialis), which innervates the facial muscles and mimic muscles. The facial nerve has motor, sensory and parasympathetic fibers. The motor fibers innervate the facial muscles, the sensory fibers innervate the $2 / 3$ front part of the tongue, and the autonomous fibers innervate the lacrimal gland. Congenital Facial Paralysis (CFP) can manifest before, during or after birth, with a frequency of 1.2-2.4/1000 (1). It causes facial asymmetry and affects eating and talking due to involvement of mimic muscles (2). Facial paralysis is a rare condition in the neonatal period, and it can be developmental or caused by by trauma. Although the most common cause is trauma during delivery, it may be observed in association with genetic syndromes and inner-ear structural abnormalities.

Congenital asymmetric crying face caused by unilateral hypoplasia or aplasia of depressor angularis oris muscle should also be considered in differential diagnosis. It is estimated that $78-91 \%$ of the CFP is due to birth trauma and $89-94 \%$ of cases are fully cured within a few weeks (3). In these patients, a multidisciplinary approach involving genetic, pediatric neurology and physiotherapy is required. Here, we present a 9-year-old girl who had CFP not related to congenital trauma and to whom we performed physiotherapy and rehabilitation program. With this case, it is aimed to review the literature about physiotherapy and rehabilitation treatment approaches for CFP. 


\section{Case Report}

It was learnt that the patient weighing $3650 \mathrm{~g}$ was delivered via caesarean section at the $40^{\text {th }}$ gestational week. It was the third pregnancy of the mother who had a medical therapeutic abortion history. There was no drug use or infectious history . In the family story, it was learnt that there was no consanguineous marriage. Post-natal physical examination revealed that the left side of the face was in a neutral state and also during crying there was no wrinkling, frowning, blinking, nostril winging, and mouth movements in the left side of the face. Left facial paralysis was diagnosed in the patient. The baby's position in the mother's womb was thought to cause damage to the left facial nerve. The patient's needle electromyography results showed that left frontal muscle input activity was not detected and the motor unit could not be ignited by voluntary contraction. Normally configured motor unit potentials were observed during voluntary contraction of the left orbicularis oris muscle. These electrophysiological findings suggested a congenital anomaly in the left facial nucleus or nerve.

The patient who did not receive physiotherapy and rehabilitation before was referred to our clinic when she was 9 years old. The informed consent was taken from the patient and her family. The manual muscle test [Medial Research Council (MRC)] was used to assess the strength and contraction of the mimic muscles during mimic movements such as smile; while the patient was in neutral posture and was closing her eyes, wiggling her forehead, twisting her nose, showing her teeth and whistling. The MRC scores are between 0 and 5 . The score of 5 (Normal) means the patient completes normal joint motion with maximum resistance to muscle gravity. The score of 0 means no contractions and full paralysis. According to this, the left side of the patient's forehead and the muscles involved in the front part of the head are MRC0, muscles around the eye are MRC1, muscles around the mouth were MRC2. House Brackmann Facial Grading Systems (HBFGS) and Sunnybrook Facial Grading Systems (SFGS) scales were used to assess facial function $(4,5$. The patient received fourth level in HBFGS scale; 20 points for resting symmetry, 72 points for voluntary movement symmetry, and 4 points for synkinesis in SFGS scale.

The patient was included in the physiotherapy and rehabilitation program for 24 weeks, 3 days/week, 1 hour/day. Positive feedbacks for both motor developments and biopsychosocial improvements were obtained after the dynamically continuing treatment program. While smiling, appearance of the muscles surrounding mouth was found almost same with the right side of the face.

\section{Discussion}

Our case was a patient with left facial paralysis without any additional diseases. In post-treatment assessments, it was observed that physiotherapy and rehabilitation had positive effects in the treatment of CFP. Improvements on the prognosis of the disease were seen with the physiotherapy and rehabilitation program. In the study by Wang et al. (6); steroid treatment was given, but no improvement was observed (6). For this reason, physiotherapy and rehabilitation is a treatment approach that should be considered in these patients. Electrotherapy and proprioceptive neuromuscular facilitation techniques should be applied to patients who have CFP. In the literature, it has been reported that children benefit from rehabilitation approaches in the treatment of CFP (7). Studies involving rehabilitation approaches such as physiotherapy, electrotherapy, biofeedback, massage, botulinum toxin and exercises (relaxation, coordination, face lift) have low levels of evidence. The purpose of rehabilitation is to reduce the muscle rigidity, and to make facial/mimic movements. It has been reported that the effects of botulinum toxin is temporary and may be more effective after nerve grafts (8). Studies on acupuncture and electrical nerve stimulation are not found in the literature. When we look at the literature, there are few studies about these kind of cases. More research on physiotherapy and rehabilitation is needed in congenital facial paralysis.

\section{Conclusion}

In conclusion, this case was presented in terms of the rare occurrence of CFP and its association with the genetic diseases. We can conclude that these patients may benefit from the physiotherapy and rehabilitation, and that these patients need guidance.

\section{Ethics}

Informed Consent: A consent form was completed by all participants.

\section{Peer-review: Externally peer-reviewed.}

\section{Authorship Contributions}

Concept: M.T., Design: B.A., A.C.Ü., M.T., B.Y., M.Ç., Data Collection or Processing: B.A., A.C.Ü, B.Y., M.Ç., Analysis or Interpretation: M.T., B.A., A.C.Ü, B.Y., M.Ç., Literature Search: M.T., B.A., A.C.Ü., B.Y., M.Ç., Writing: M.T., B.A., A.C.Ü., B.Y., M.Ç.

Conflict of Interest: No conflict of interest was declared by the authors.

Financial Disclosure: The authors declared that this study received no financial support.

\section{References}

1. Terzis JK, Anesti K. Developmental facial paralysis: a review. Journal of Plastic, Reconstructive \& Aesthetic Surgery 2011;64:1318-33.

2. Elden Lisa M, Zur Karen B. Congenital Malformations of the Head and Neck. Elsevier 2014;57-9.

3. Shapiro NL, Cunningham MJ, Parikh SR, Eavey RD, Cheney ML. Congenital unilateral facial paralysis. Pediatrics 1996;97:261-4. 
4. Ross BG, Fradet G, Nedzelski JM. Development of a sensitive clinical facial grading system. Otolaryngology-Head and Neck Surgery 1996;114:380-6.

5. Evans RA, Harries ML, Baguley DM and Moffat DA. Reliability of the House and Brackmann grading system for facial palsy. J Laryngol Otol 1989;103:1045-6.
6. Wang CH, Chang YC, Shih HM, Chen CY, Chen JC. Facial palsy in children: emergency department management and outcome. Pediatric emergency care 2010;26:121-5.

7. Pavlou E, Gkampeta A, Arampatzi M. Facial nerve palsy in childhood. Brain Dev 2011;33:644-50.

8. Ciorba A, Corazzi V, Conz V, Bianchini C, Aimoni C. Facial nerve paralysis in children. World J Clin Cases 2015;3:973-79. 